\title{
A unique late complication with the use of calcium hydroxylapatite filler in facial lipoatrophy rehabilitation
}

\author{
Raffaele Rauso ${ }^{1,2}$ \\ ${ }^{1}$ Univeristy of Foggia, 71121 Foggia, Italy. \\ 2 Department of Plastic Surgery, La Sapienza University, 00185 Rome, Italy.
}

Address for correspondence: Dr. Raffaele Rauso, Centro Polispecialistico Santa Apollonia, Department of Aesthetic Plastic and Craniofacial Surgery, Via Martiri del Dissenso 47, 81055 Santa Maria Capua Vetere CE, Italy. E-mail: dr.raffaele.rauso@gmail.com

\section{Sir,}

Radiesse (Merz Aesthetics, Franksville, WI, USA) is an injectable filler material composed of synthetic calcium hydroxylapatite (CaHA) microspheres suspended in an aqueous carrier gel. Cosmetic use of Radiesse in facial rejuvenation is well-known. Treatment sites amenable to calcium hydroxylapatite $(\mathrm{CH})$ injection include the naso-labial folds, marionette lines, perioral lines, prejowl sulcus, zygoma and malar eminence, tear trough depressions, nose, chin, acne scars, and it is also Food and Drug Administration-approved for facial augmentation in HIV patients with facial lipo-atrophy. ${ }^{[1]}$

Calcium hydroxylapatite filler enjoy an excellent safety record. The adverse events reported are similar to those observed with other short-acting fillers such as hyaluronic acid. There is no evidence of granuloma formation occurring with CaHA. ${ }^{[1]}$ Although, presence of visible skin nodules has been reported, they are related to techniques, especially due to superficial injection of $\mathrm{CH}$ or its inappropriate use.

We describe a unique unreported complication, related to $\mathrm{CH}$ filler injection in an HIV positive patient. A 37-year-old, HIV positive, Caucasian male patient was referred to our University Hospital for facial lipo-atrophy rehabilitation [Figure 1]. We performed, as per our protocol, ${ }^{[2]}$ the rehabilitation in one session injecting $7.5 \mathrm{~mL}$ of $\mathrm{CH}$ filler. After 10 days postinjection swelling and hematoma resolved [Figure 2]. Three weeks later, the patient came back to us with a complaint of a soft tissue swelling, involving the areas where the filler was injected [Figure 3]. The swelling was soft, nontender with sudden onset in the morning after waking up from sleep. A bromelina based therapy was prescribed for a week (Ananase, Rottapharm S.p.a., Milano) by us. After 2 weeks the swelling resolved completely with no recurrence in 8 months of follow-up [Figure 4]. To

\begin{tabular}{|l|l|}
\hline \multicolumn{2}{|c|}{ Access this article online } \\
\hline Quick Response Code: & Website: \\
\hline & www.parjournal.net \\
\cline { 2 - 2 } & \\
\hline & \\
\hline
\end{tabular}

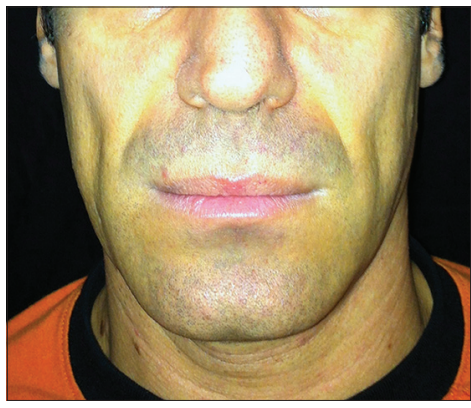

Figure 1: Preoperation photo of the patient

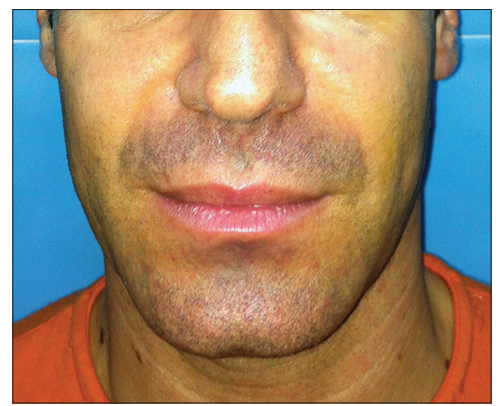

Figure 2: Result at the 10th days after calcium hydroxylapatite injection

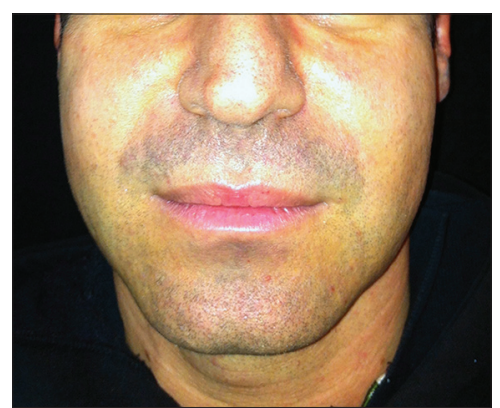

Figure 3: Swelling appeared at the 21st day postinjection

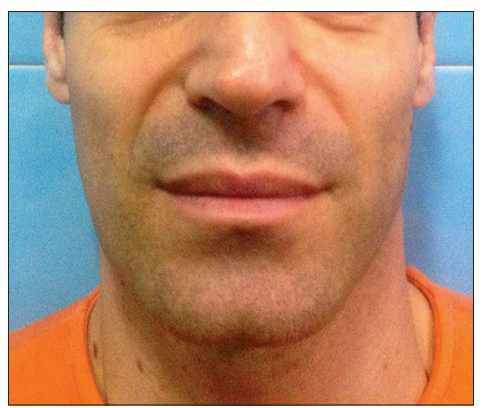

Figure 4: After 2 more weeks the swelling gradually disappeared 
the best of our knowledge and after extensive literature search we could not determine the reason for this complication nor has such adverse effect ever reported in the literature.

\section{REFERENCES}

I. Graivier MH, Bass LS, Busso M, Jasin ME, Narins RS, Tzikas TL. Calcium hydroxylapatite (Radiesse) for correction of the mid- and lower face: consensus recommendations. Plast Reconstr Surg 2007; 120:55S-66S.
2. Rauso R, Curinga G, Rusciani A, Colella G, Amore R, Tartaro G. Safety and efficacy of one-step rehabilitation of human immunodeficiency virus-related facial lipoatrophy using an injectable calcium hydroxylapatite dermal filler. Dermatol Surg 2013;39:1887-94.

How to cite this article: Rauso R. A unique late complication with the use of calcium hydroxylapatite filler in facial lipoatrophy rehabilitation. Plast Aesthet Res 2014;1:122-3.

Source of Support: Nil, Conflict of Interest: None declared.

Received: 23-06-2014; Accepted: 05-08-2014 